TITLE:

\title{
Discrete element method analysis of single wheel performance for a small lunar rover on sloped terrain
}

\section{$\operatorname{AUTHOR}(S)$ :}

Nakashima, H.; Fujii, H.; Oida, A.; Momozu, M.; Kanamori, H.; Aoki, S.; Yokoyama, T.; Shimizu, H.; Miyasaka, J.; Ohdoi, K.

\section{CITATION:}

Nakashima, H.... [et al]. Discrete element method analysis of single wheel performance for a small lunar rover on sloped terrain. Journal of Terramechanics 2010, 47(5): 307-321

\section{ISSUE DATE:}

2010-10

URL:

http://hdl.handle.net/2433/126852

\section{RIGHT:}

(c) 2010 ISTVS Published by Elsevier Ltd.; この論文は出版社版でありま せん。引用の際には出版社版をご確認じ利用ください。; This is not the published version. Please cite only the published version. 


\title{
Discrete element method analysis of single wheel performance for a small lunar rover on sloped terrain
}

\author{
H. Nakashima ${ }^{\text {a,* }}$, H. Fujii ${ }^{\text {b }}$, A. Oida ${ }^{\text {a }}$, M. Momozu ${ }^{\text {c, }}$ \\ H. Kanamori ${ }^{\text {d }}$, S. Aoki ${ }^{d}$, T. Yokoyama ${ }^{\text {e }}$, H. Shimizu ${ }^{\text {a }}$, \\ J. Miyasaka ${ }^{\text {a }}$, K. Ohdoi ${ }^{\text {a }}$ \\ ${ }^{a}$ Division of Environmental Science $\mathcal{E}$ Technology, Graduate School of Agriculture, \\ Kyoto University, Kyoto 606-8502, JAPAN \\ ${ }^{\mathrm{b}}$ Toyota Motor Corporation, Toyota, Aichi 471-8571, JAPAN \\ ${ }^{\mathrm{c}}$ Bridgestone Corporation, Kodaira, Tokyo 187-8531, JAPAN \\ ${ }^{\mathrm{d}}$ Institute of Technology, Shimizu Corporation, \\ Koto-ku, Tokyo 135-8530, JAPAN \\ ${ }^{\mathrm{e}}$ College of Science $\mathcal{E}$ Engineering, Ritsumeikan University, \\ Kusatsu, Shiga 525-8577, JAPAN
}

\begin{abstract}
The purpose of this study is to analyze the performance of a lugged wheel for a lunar micro rover on sloped terrain by a 2D discrete element method (DEM), which was initially developed for horizontal terrain. To confirm the applicability of DEM for sloped terrain locomotion, the relationships of slope angle with slip, wheel sinkage and wheel torque obtained by DEM, were compared with experimental results measured using a slope test bed consisting of a soil bin filled with lunar regolith simulant. Among the lug parameters investigated, a lugged wheel with rim diameter of $250 \mathrm{~mm}$, width of $100 \mathrm{~mm}$, lug height of $10 \mathrm{~mm}$, lug thickness of $5 \mathrm{~mm}$, and total lug number of 18 was found, on average, to perform excellently in terms of metrics, such as slope angle for $20 \%$ slip, power number for self-propelled point, power number for 15-degree-slope and power number for $20 \%$ slip. The estimation of wheel performance over sloped lunar terrain showed an increase in wheel slip, and the possibility exists that the selected lugged wheel will not be able to move up a slope steeper than 20 degrees.
\end{abstract}

Key words: Computational mechanics; Discrete element method; Soil-wheel system; Slope; Wheel performance; Lug; Lunar rover

* Corresponding author. Tel.: +81-75-753-6164; Fax.: +81-75-753-6165.

Email address: hiron@kais . kyoto-u.ac.jp (H. Nakashima). 
friction coefficient between soil elements

$\mu^{L} \quad$ friction coefficient between soil element and wheel (or lug) element

$\mu^{w} \quad$ friction coefficient between soil element and wall element

$\omega$ angular velocity of wheel

$\phi \quad$ angle of internal friction

$\rho \quad$ density of soil element

$\rho_{d} \quad$ dry bulk density

$\rho_{e} \quad$ representative bulk density for damping coefficient calculation in DEM

$\rho_{\max } \quad$ maximum dry bulk density

$\rho_{\text {min }} \quad$ minimum dry bulk density

$\theta \quad$ inclination angle of slope

$\theta_{20 \%} \quad$ inclination angle of slope at $20 \%$ slip

$A_{l} \quad$ total section area of lugs, such that $L_{n} B L_{T}$

$A_{w} \quad$ area of possible contacting surface of wheel rim, such that $\pi B D_{0}$

$B \quad$ width of wheel

c cohesion

$C_{l} \quad$ percent cover of total section area of lugs over area of wheel surface without lugs, such that $C_{l}=A_{l} / A_{w}$

$C_{n} \quad$ normal damping coefficient in DEM

$C_{t} \quad$ tangential damping coefficient in DEM

$D \quad$ outermost diameter of a wheel inclusive of lug height

$D_{0} \quad$ rim diameter of a wheel

$D_{r} \quad$ relative density of lunar regolith simulant

$f_{x}^{+} \quad$ positive $x$-component of contact reaction w. r. t. local axis

$f_{x}^{-} \quad$ negative $x$-component of contact reaction w. r. t. local axis

$H$ gross traction in slope locomotion, obtained as $H=\sum f_{x}^{+}$

$i \quad$ slip of a wheel in slope locomotion, such that $i=1-\left(V_{s} / r_{w} \omega\right)$

$K_{n} \quad$ normal spring constant between soil elements

$K_{n}^{L} \quad$ normal spring constant between soil element and wheel (or lug) element

$K_{n}^{w} \quad$ normal spring constant between soil element and wall element

$K_{t} \quad$ tangential spring constant between soil elements

$K_{t}^{L} \quad$ tangential spring constant between soil element and wheel (or lug) element

$K_{t}^{w} \quad$ tangential spring constant between soil element and wall element

$L_{H} \quad$ height of lug

$L_{n} \quad$ total number of lug for a wheel

$L_{T} \quad$ lug thickness

$m_{e} \quad$ equivalent mass of soil element, defined as $\rho_{e} \times$ (volume of largest soil element)

$P \quad$ drawbar pull

$P_{d} \quad$ net traction in slope locomotion, obtained as $P_{d}=H-R_{r}$ $P N \quad$ power number, defined by $T \omega / W V_{a}$ pull coefficient, dimensionless, with respect to drawbar pull $P$ or $P_{x}$ 


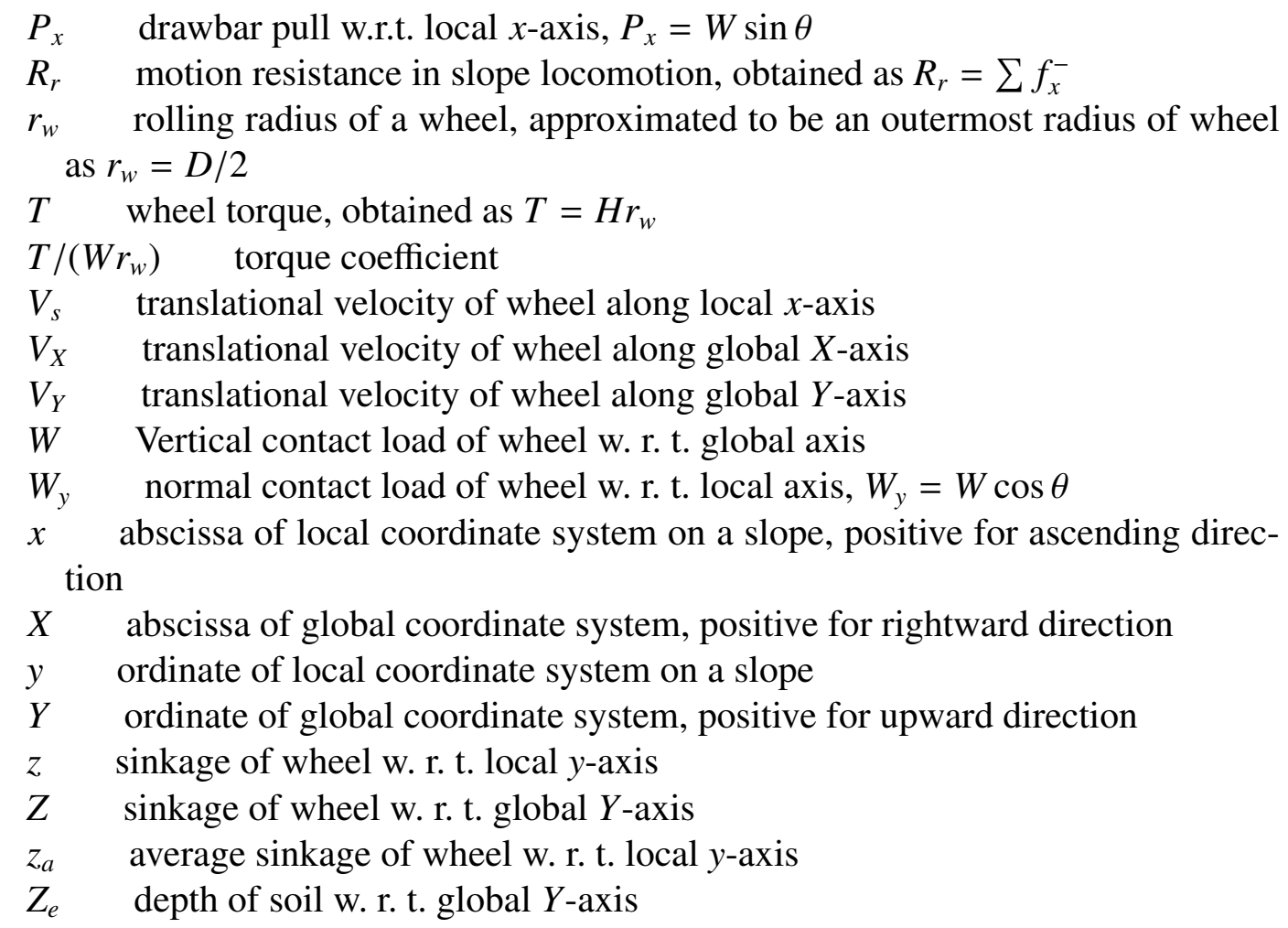

\section{Introduction}

The Selenological and Engineering Explorer (SELENE) was a Japanese lunar exploration project that ran from December 2007 to June 2009. Using a remote sensing system on an observational orbiter, named "Kaguya," SELENE obtained the first precise data on lunar surface geometry and mineral composition. A follow-up project, SELENE-2, is now under discussion at JAXA. Its main mission objectives would be to land on the Moon and obtain in situ geological samples using a small robotic rover [1]. To keep the payload of the H-II rocket to a minimum, the rover vehicle must be as small and light as possible. The envisaged maximum mass of the rover is $100 \mathrm{~kg}$ [2]. The rover can use either wheels or tracks for locomotion.

Since one of the candidate landing sites for SELENE-2 would be around the central peak of a crater, which should provide abundant geological information on the origin of the Moon, initial discussions on terramechanics for SELENE-2 had been focused on the mobility of a rover over the soft powdery lunar regolith accumulated over the peak. For this reason, an experimental investigation was started in an indoor horizontal soil bin with a lunar regolith simulant at Tsukuba Space Center (TSC) of NASDA (currently JAXA). Experiments with a rigid wheel resembling a conventional tire with no lugs, showed difficulty of locomotion even on horizontal terrain condition for a smaller drawbar load [3]. Moreover, developing a performance prediction model for such a 3D wheel shape proved difficult. Therefore, we 
decided to develop simpler wheels with straight lugs, which may be approximated as 2D shapes, and a PC-based 2D performance prediction model for such wheels. For these reasons, our study focused on a lugged wheel.

There are only a few published reports on the interaction between wheels and planetary terrain such as lunar regolith. Freitag et al. [4] investigated several flexible wheels of different tread patterns for the Apollo Lunar Roving Vehicle (LRV) and reported that a uniform or near-uniform distribution of contact pressure was desirable and they found no particular advantage in reducing the contact pressure below $3.45 \mathrm{kPa}$ for their tested flexible wheels. Moreover, the performances of several LRV wheels were reported by using a single-wheel dynamometer system and a wheel with 50\% covered tread pattern showed slightly superior performance in Lunar Soil Simulant test [5]. Successively, two LRV wheels were tested to determine the influence of wheel speed, acceleration, travel direction, the presence of a fender, or wheel load [6]. LRV wheels were however much larger than those envisaged for our lunar micro rover. Their study of the wheel performance on a slope of prototype rover models used three metrics: the pull coefficient, torque coefficient, and the power number [4-6].

Moreover, the experiences of manufacturing of candidate wheels for Apollo LRV were recently reported, and the decision processes for selection of LRV wheels were summarized in detail [7]. The computational model NWVPM (Nepean Wheeled Vehicle Performance Model) was used to predict the mobility of various wheels for LRV, and its predictions were accurate within the range of soil conditions published in some reports [8].

For small wheels, Richter and Hamacher [9] attempted to simulate the locomotion performance of microrovers on the Martian surface for the European Space Agency (ESA) by applying Bekker's formula. They constructed a $19.2 \mathrm{~cm}$ diameter lugged rigid wheel, designed for a mobile instrument deployment device vehicle with a mass of $8.6 \mathrm{~kg}$, that applies a load of $7.92 \mathrm{~N}$ per wheel. Richter et al. further developed a predictive wheel-soil interaction model for Mars rovers using Bekker's approach with a combination of the nonlinear slip-sinkage relationship and the contact area based modification of the shear deformation modulus $K$ [10]. Their modified model became sufficiently accurate to predict the performance of the Solar Powered Exploration Rover (SOLERO) and JPL Mars Exploration Rover (MER) wheels on DLR Mars Soil Simulant C (MSS-C) soil.

Recently, experimental approaches to wheel performance on sloped terrain have been developed using a sloped test bed with a lunar regolith simulant. A possible star shaped wheel with specially arranged lugs was reported, but a detailed evaluation of power consumption was not included [11]. Moreover, a specially designed small elastic wheel demonstrated superior performance to the rigid lugged wheel [12]. 
The discrete, or distinct, element method (DEM), initially proposed by Cundall [13], has become popular as a computational tool for dynamics of particles or powders in science and engineering. In the assembly of particles, there should be some effects of the potential forces from ambient particles other than the locally contacting. However, the present computational capability is still limited in considering all such forces. Thus, in DEM, the local contact reaction of two contacting elements is only considered.

In principle, DEM is based on the equation of motion, where all forces (such as contact reaction and body force) acting on the element of interest are added to the force term. After calculating all forces for all elements, the equations of motion are integrated to obtain subsequent velocities and displacements. The DEM solution is generally based on an explicit integration whose stability is conditional [13], which implies that the time step should be as small as possible. Moreover, for stable analysis, there exists the allowable range of time step in terms of the computational cost.

The normal contact reaction is calculated by contact models, such as the linear spring model [13] and Hertz contact model [14]. Similarly, both the linear spring model [13] and Mindlin-Deresiewicz contact model [15] are applied in calculating the tangential contact reaction. Viscous reaction forces are also assumed in both the normal and tangential directions. The shape of discrete elements can freely be defined, but simple shapes, such as a circle for $2 \mathrm{D}$, or sphere for $3 \mathrm{D}$, are most popular in terms of the detection of contact [13]. Other elemental shapes, such as an ellipse [16], polygon [17], or a clump of two or more circles [18] have also been applied in 2D DEM in the past.

Although a strict analysis of DEM based on the real element radius of soil particles might be ideal [19], at present, the radius of the element can not be of the same order as that in the target soil particles because of the computational cost. In this sense, the DEM element is a virtual element with a representative element radius that is larger than the real soil particles [20]. Therefore, the parameters used in the contact model of DEs should be determined or calibrated with comparative experiments using similar particle conditions.

Off-road wheel performance could be analyzed with sufficient accuracy [3, 18, 19, 21-25] by DEM. Furthermore, the performance of a lugged wheel on a horizontal lunar terrain could be predicted by simply reducing the gravity from 1 to $1 / 6$ G, while holding other DEM parameters-such as spring constants and damping coefficients-constant $[24,25]$. Using ellipsoid for soil elements, application of 3D DEM to the wheel of the MER under various gravities was recently reported [26]. The results indicated that the wheel torque increased almost linearly with gravity. The authors' group verified the use of constant DEM parameters in low gravity conditions through analysis of sand pile formation under low gravity by performing a DEM simulation and airplane experiments [27]. Note that the analysis of DEM for 


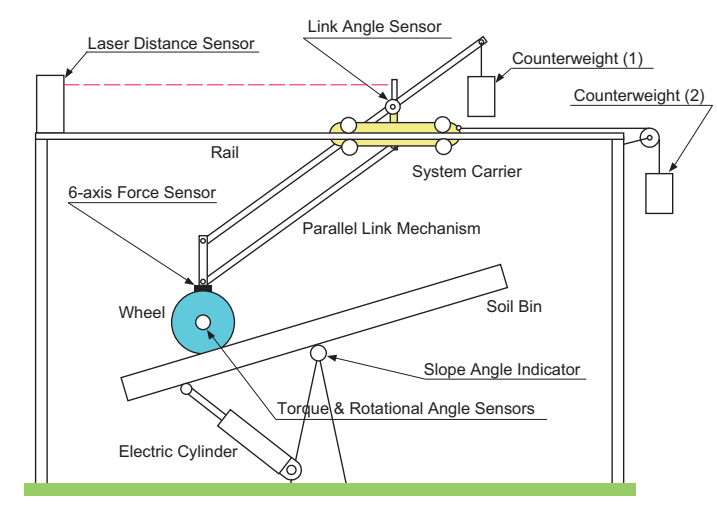

Fig. 1. Schematic diagram of the sloped soil bin and single wheel dynamometer

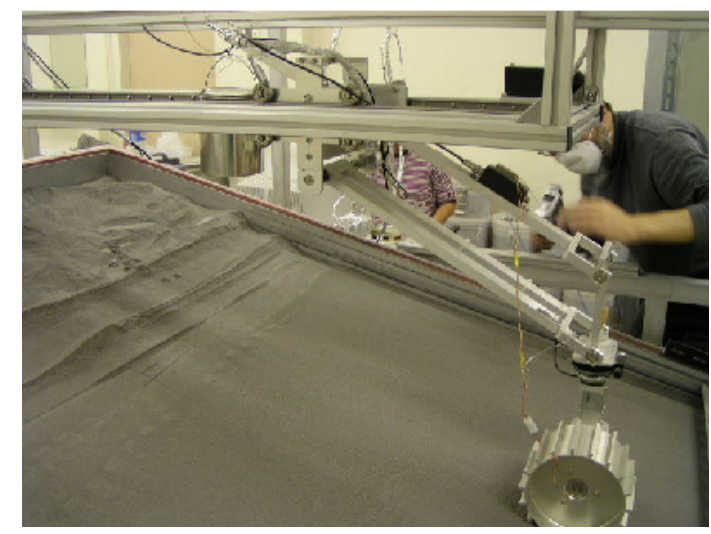

Fig. 2. View of the soil bin and single wheel dynamometer

sand pile formation under lunar gravity conditions was also reported but there was no comparison with experimental results [28].

The purpose of this study is to analyze the performance of a lugged wheel for a lunar micro rover on sloped terrain using the 2D DEM procedure previously developed for horizontal terrain [24]. The analysis accuracy will be confirmed by experiments using a sloped test bed. The parameters for the lugged wheel are numerically investigated in terms of metrics, such as slope angle for $20 \%$ slip and power numbers, and a candidate wheel configuration is selected. Moreover, wheel performance on a sloped lunar terrain is predicted by DEM analysis with reduced relative gravitational acceleration using the selected lugged wheel configuration. 


\section{Experiments with single wheel performance on the slope}

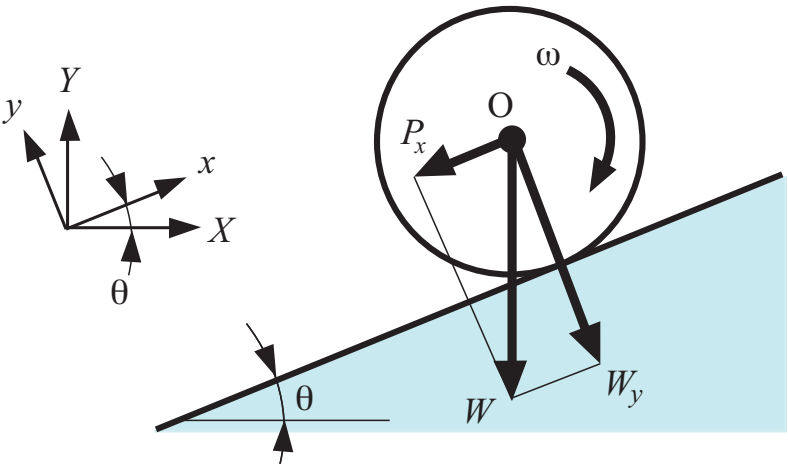

Fig. 3. Wheel travel on a slope

\subsection{Sloped soil bin with a single wheel dynamometer}

A sloped mobility test bed, consisting of a wide soil bin with effective inner dimensions of $1.5 \mathrm{~m}$ (width), $2.0 \mathrm{~m}$ (length), and $0.2 \mathrm{~m}$ (depth), which could be tilted, was constructed at Chofu Aerospace Center (CAC), JAXA [29]. The soil bin is axially rotated using a linear electrically driven actuator. A schematic configuration of the experimental facility is shown in Fig. 1.

A horizontal frame of the wheel carrier was constructed over the sloped soil bin. A target wheel attached at the end of a parallel link mechanism can freely sink vertically, with its weight controlled by the counterweight (1). Another counterweight (2) is adjusted to counteract the motion resistance of the system carrier so that the applied drawbar condition can be controlled properly. A six axis force sensor monitors the motion resistance by measuring the horizontal reaction. The vertical sinkage of a wheel is measured indirectly with a rotation angle sensor as the difference in the angle at the hinge point of the parallel link mechanism. Finally, a laser distance sensor monitors the horizontal travel distance of the wheel. Figure 2 shows a photo taken during the experiment.

Figure 3 shows the climbing wheel motion on sloped terrain with slope angle $\theta$. While we define the conventional global coordinate system $(X, Y)$, the local coordinate system of $(x, y)$ is defined such that the $x$-axis is taken along the sloped surface as shown in Fig. 3.

In this simulation of wheel travel on a slope, the inputs are slope angle $\theta$, constant wheel rotation velocity $\omega$, and vertical contact load of the wheel $W$. In accordance with wheel dynamics over soil elements under contact, the wheel travels over the soil surface with the local travel velocity $V_{s}$, which can be calculated with respect 
to a unit time step of numerical integration as

$$
V_{s}=V_{X} \cos \theta+V_{Y} \sin \theta
$$

where $V_{X}$ is the horizontal travel velocity, $V_{Y}$ is the vertical velocity, and $\theta$ is the slope angle. Note that $V_{X}$ can be obtained from the distance signal of the laser distance sensor, and $V_{Y}$ is calculated using the output from the angle sensor of the parallel link rotation in the experiment (see Fig. 1).

The slip $i$ of a wheel can then be expressed using $V_{s}$ such that

$$
i=1-\frac{V_{s}}{r_{w} \omega}
$$

where $r_{w}$ is the free rolling radius of the wheel, assumed as the outer radius of the wheel $D / 2$ including lug height $L_{H}$, since the measurement of free rolling radius is difficult for relatively soft soil conditions as in this study.

The pull coefficient is defined as the ratio of drawbar pull $P_{x}$ to the vertical contact load of wheel $W$, i.e., $P_{x} / W$. As shown in Fig. 3, the pull coefficient is not a performance variable but a state variable, which can be expressed as $P_{x} / W=\sin \theta$ for sloped terrain locomotion. The torque coefficient can be expressed as the ratio of wheel torque $T$ to a product of the vertical contact load $W$ and the rolling radius of the wheel $r_{w}$, i.e., $T / W r_{w}$. The power number $P N$ measures the power consumption per unit of distance per unit of wheel weight in the locomotion from the starting point to the end point, and can be defined as follows [4]:

$$
P N=\frac{T \omega}{W V_{s}}
$$

A wheel performs better if the torque coefficient decreases and if the power numbers decrease.

\subsection{Wheel specifications}

Various test wheels made of aluminum were used in the experiments $[23,24]$. Their specifications are summarized in Table 1 , where $D$ is the total wheel diameter, $D_{0}$ is the rim diameter without lug, $B$ is the width of the wheel, $L_{H}$ is the height of the lugs, $L_{T}$ is the thickness of the lugs, and $L_{n}$ is the total number of lugs per wheel. The coefficient $C_{l}$ represents the percent cover of the wheel lugs such that:

$$
C_{l}=\frac{A_{l}}{A_{w}}=\frac{L_{n} B L_{T}}{\pi B D_{0}}=\frac{L_{n} L_{T}}{\pi D_{0}} \times 100(\%)
$$


Table 1

Wheel specifications for slope locomotion

\begin{tabular}{cccccccc}
\hline Wheel No. & $D(\mathrm{~mm})$ & $D_{0}(\mathrm{~mm})$ & $B(\mathrm{~mm})$ & $L_{H}(\mathrm{~mm})$ & $L_{T}(\mathrm{~mm})$ & $L_{n}$ & $C_{l}(\%)$ \\
\hline 1 & 220 & 200 & 50 & 10 & 5 & 18 & 14.3 \\
$2^{\dagger}$ & 220 & 200 & 100 & 10 & 5 & 18 & 14.3 \\
3 & 220 & 200 & 150 & 10 & 5 & 18 & 14.3 \\
4 & 170 & 150 & 100 & 10 & 5 & 18 & 19.1 \\
5 & 270 & 250 & 100 & 10 & 5 & 18 & 11.5 \\
6 & 210 & 200 & 100 & 5 & 5 & 18 & 14.3 \\
7 & 220 & 200 & 100 & 10 & 5 & 36 & 28.6 \\
8 & 240 & 200 & 100 & 20 & 5 & 18 & 14.3 \\
9 & 220 & 200 & 100 & 10 & 10 & 18 & 28.6 \\
\hline
\end{tabular}

$\dagger$ Wheel No. 2 is the base condition of reference.

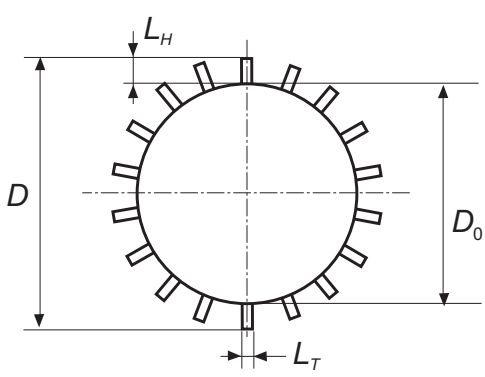

(a)

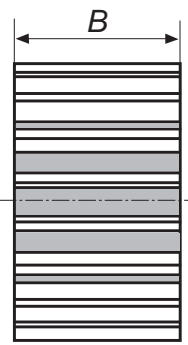

(b)

Fig. 4. Lug parameters

\subsection{Experimental conditions}

In the experiment, a lunar regolith simulant, FJS-1, prepared by Shimizu Corporation, was used to fill the soil bin to a depth of $10 \mathrm{~cm}$, which was the same depth as in previous experiments on horizontal terrain [3,23]. Since the data of in situ observation in the Apollo 15 mission [30] indicated that there might be a relative density layer of very dense (hard) in lunar terrain around a depth of $10 \mathrm{~cm}$ or more, the depth of the simulant in the experiments was set to $10 \mathrm{~cm}$, which assumes the existence of hardpan below $10 \mathrm{~cm}$. The physical properties of FJS-1 are summarized 
Table 2

Physical property of lunar regolith simulant FJS-1

\begin{tabular}{lr}
\hline Specific gravity of particle & 2.94 \\
Minimum bulk density $\rho_{\min }\left(\mathrm{g} / \mathrm{cm}^{3}\right)$ & 1.4 \\
Maximum bulk density $\rho_{\max }\left(\mathrm{g} / \mathrm{cm}^{3}\right)$ & 2.0 \\
Cohesion c $(\mathrm{kPa})$ & 2.55 \\
Angle of internal friction $\phi(\mathrm{deg})$ & 37.2 \\
\hline
\end{tabular}

Table 3

Experimental conditions

\begin{tabular}{lr}
\hline Vertical wheel load $W(\mathrm{~N})$ & $9.8,14.7,19.6$ \\
Slope angle $\theta(\mathrm{deg})$ & $0,10,15,20,25$ \\
Angular velocity of wheel $\omega(\mathrm{rad} / \mathrm{s})$ & $0.1,0.2,0.3$ \\
\hline
\end{tabular}

in Table 2 [29].

Before each experiment, the simulant was manually raked and moved up and down within the soil bin and leveled with a leveling plate. The dry bulk density $\rho_{d}$ in the experiments were monitored frequently by a vane shear device at three locations on the soil surface. The obtained shear torque was converted to $\rho_{d}$ based on the calibration, which represented the value of $\rho_{d}$ at a depth of $4 \mathrm{~cm}$. Throughout the experiments, the average of $\rho_{d}$ was found to be $1.48 \mathrm{~g} / \mathrm{cm}^{3}$. The relative density $D_{r}$ can then be calculated by

$$
D_{r}=\frac{\rho_{\max }}{\rho_{d}}\left(\frac{\rho_{d}-\rho_{\min }}{\rho_{\max }-\rho_{\min }}\right) \times 100(\%)
$$

From Eq. (5), $D_{r}$ could be experimentally obtained as $17.4 \%$. Note that this relative density condition is classified as "loose" $[4,30]$.

Shear strength parameters of FJS-1, such as cohesion and angle of internal friction, were obtained by conventional triaxial compression test with confining pressures similar to the reported measurement for JSC-1 [31]. Cohesion is thought to be related to inter particle attractive force, which becomes dominant for particles of smaller diameter [29].

Experiments were conducted using the conditions listed in Table 3. The vertical contact load contains the wheel weight. Experiments were repeated twice under the same conditions.

In the numerical simulation, the vertical contact load $W$ was held constant for all slope angles, as was done in the experiment. The drawbar load $P_{x}$ is applied as the slope angle $\theta$ is changed, based on the relationship of $P_{x}=W \sin \theta$. The ratio of 
Table 4

Variation of ratio of $P_{x} / W$ on the slope

\begin{tabular}{cc}
$\theta(\mathrm{deg})$ & $P_{x} / W$ \\
\hline 0 & 0.0 \\
5 & 0.0872 \\
10 & 0.1736 \\
15 & 0.2588 \\
20 & 0.3420 \\
25 & 0.4226 \\
\hline
\end{tabular}

$P_{x} / W(=\sin \theta)$ is summarized in Table 4. Acceleration forces are assumed to be negligible in the table.

\section{DEM analysis of lugged wheel performance for sloped terrain}

We previously reported the applicability of DEM for analyzing tractive performance of rigid lugged wheels for a lunar microrover on horizontal surfaces [23,24]. The analysis of wheel performance by DEM for various slopes is summarized in this section.

\subsection{Outline of analysis}

Since the computational cost is still high in the application of 3D analysis, this study applied 2D DEM. The parameters for contact reaction are the spring constant, the viscous coefficient in normal and tangential directions, and the friction coefficient. This study uses a trial-and-error approach for an initial parameter guess, as in the previous study [24]. The justification of the selected parameter values is then verified by comparing the DEM with experimental results, as shown in Section 4.

Small DEM elements, embedded virtually at lug positions, are used for the contact check and contact reaction calculation between wheel lugs and soil [24]. All reactions from lug elements are added as the reaction of the wheel element.

Other small virtual DEM elements are embedded in three walls-two sides and one bottom-of the soil bin to facilitate the generation of sloped terrain conditions. These virtual wall elements are used only for contact calculation at the soil bin walls, and they do not move or rotate from contact reaction. 


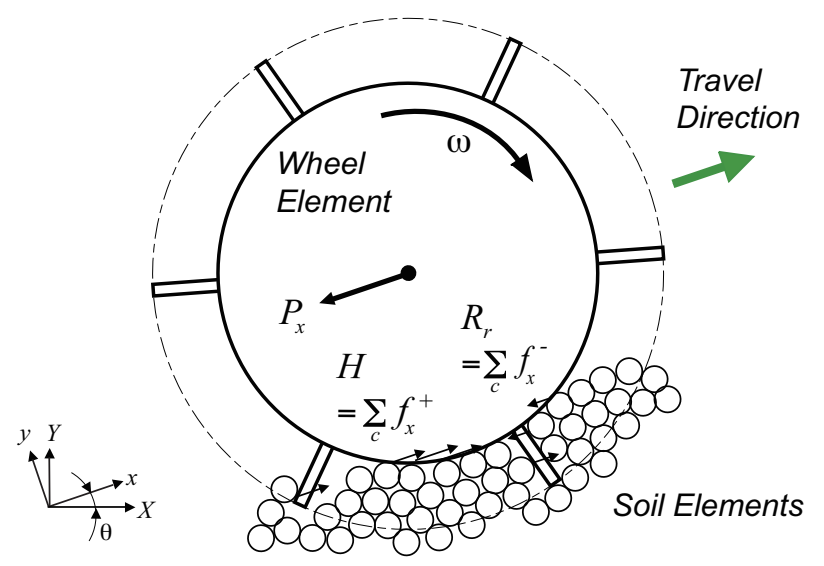

Fig. 5. Tractive effort and motion resistance on the slope for DEM

\subsection{Wheel performance analysis on the slope}

Each $x$-component of the contact reaction force $f_{x}$ on a wheel and lug element is summed to obtain either the calculated gross traction $H$ (if $f_{x} \geq 0$ ), or motion resistance $R_{r}$ (if $f_{x}<0$ ), with respect to the local $x$-axis as shown in Fig. 5 .

After obtaining the gross traction $H$ and the motion resistance $R_{r}$ with DEM, we calculate the net traction $P_{d}$ using $P_{d}=H-R_{r}$ with respect to the local $x$-coordinate axis on the slope.

\subsection{Preparation of DEM simulation}

The parameters used in DEM analysis are summarized in Table 5. Note that the density of the regolith element of $1.55 \mathrm{~g} / \mathrm{cm}^{3}$, which corresponds to the value of the bulk density at about $5 \mathrm{~cm}$ below the lunar regolith surface [30], is used for calculating the damping coefficient.

The elemental density $\rho\left(\mathrm{g} / \mathrm{cm}^{3}\right)$ was calculated based on the initially generated depth of the regolith element $Z_{e}$ using the following empirical relation from the Apollo program [30]:

$$
\rho=1.89 \times \frac{Z_{e}+1.69}{Z_{e}+2.9}
$$

where $Z_{e}$ is the depth of lunar regolith element $(\mathrm{cm})$.

The spring constants $\left(K_{n}, K_{t}\right)$ were initially set to the same values as in the previous study on wheel performance on horizontal terrain $[23,24]$. The friction coefficient between soil DEs $\mu$ is from the angle of internal friction of FJS-1. Friction coefficient of the soil bin walls $\mu^{w}$ is set by assuming the composition of wall to be 
Table 5

Parameters in DEM simulation

\begin{tabular}{|c|c|}
\hline Number of elements for regolith & 6986 \\
\hline Diameter of the regolith element, random $(\mathrm{mm})$ & $2.8,3.2,3.6,4.0$ \\
\hline Regolith elemental density $\left(\mathrm{g} / \mathrm{cm}^{3}\right)$ & $1.55^{\dagger}$ \\
\hline Mass of the wheel (g) & 500 \\
\hline Diameter of the lug element (mm) & 2.5 \\
\hline Diameter of the wall element (mm) & 2.5 \\
\hline Slope angle $\theta(\mathrm{deg})$ & $0,5,10,15,20,25$ \\
\hline Vertical contact load $W(\mathrm{~N})$ & $9.8,14.7,19.6$ \\
\hline Drawbar load $P_{x}(\mathrm{~N})$ & $W \sin \theta$ \\
\hline Angular velocity of the wheel $\omega(\mathrm{rad} / \mathrm{s})$ & 0.138 \\
\hline Duration of soil consolidation (s) & $1.0,6.0$ \\
\hline Duration of vertical sinkage (s) & 1.0 \\
\hline Simulation time for wheel travel (s) & 40.0 \\
\hline Time step increment (s) & 0.00005 \\
\hline Normal spring constants $K_{n}, K_{n}^{w}$ and $K_{n}^{L}(\mathrm{~N} / \mathrm{m})$ & 10,000 \\
\hline Tangential spring constants $K_{t}, K_{t}^{w}$ and $K_{t}^{L}(\mathrm{~N} / \mathrm{m})$ & 500 \\
\hline Friction coeff. between regolith elements $\mu$ & 0.75 \\
\hline Friction coeff. for wall contact $\mu^{w}$ & 0.75 \\
\hline Friction coeff. for wheel contact $\mu^{L}$ & 0.5 \\
\hline
\end{tabular}

$\dagger$ This density value is used for damping coefficient calculation.

soil, while that for the wheel and lug contact $\mu^{L}$ is the same as in the previous study. Damping coefficients were calculated using the critical damping formula, such that $C_{n}=2 \sqrt{m_{e} K_{n}}$ for a normal damper and $C_{t}=2 \sqrt{m_{e} K_{t}}$ for a tangential damper, where $m_{e}$ is an equivalent mass representatively calculated by using $\rho=$ $1.55 \mathrm{~g} / \mathrm{cm}^{3}, B$ and $r_{\max }$.

Moreover, in Table 2, the lunar regolith simulant FJS-1 shows cohesion as well as internal friction. As reported in our previous studies [23,24], DEM results showed sufficient accuracy when compared with the experimental result, although the effect of cohesion was not explicitly introduced in the contact model in our DEM analysis. The introduction of cohesive reaction in a DEM contact model can easily be realized by an additional parallel tensile spring model [32], or an internal locking force model [33].

In the preliminary DEM analysis, the wheel rotational velocity did not exhibit a 
significant effect on wheel performance parameters, such as slip, gross traction, and net traction. Thus, the data from the previous paper [24], of $\omega=0.138 \mathrm{rad} / \mathrm{s}$, is used in the analysis unless otherwise stated. Table 1 also lists the parameters for lug configuration and wheel diameter used in DEM.

DEM simulation for wheel performance is divided into four stages: (i) initial soil consolidation by their own weight of elements with the horizontal soil bin; (ii) rotation of the soil bin to the required slope angle; (iii) secondary consolidation with free wheel sinkage on to sloped soil surface and (iv) wheel travel simulation on sloped terrain [23].

In the first stage, the preparation of soil discrete elements is performed by analyzing the consolidation of soil DEs with their own weight of the elements from the initial regular configuration of DEs in the soil bin. The preparation of the soil condition in the experiment, however, involves manual mixing of the simulant with a hand rake, and leveling the disturbed surface by sliding a leveling blade over the edge of the soil bin. However, the present 2D DEM cannot include such preparation procedures due to computational cost as well as the limited degrees of freedom of the analysis.

At the wheel travel stage, the wheel sinkage was calculated as the local average sinkage $z_{a}$ from the reference where the wheel begins to rotate. This avoids the difficulty of defining zero wheel sinkage with various lug conditions running over the uneven sloped surface of random soil DEs.

\section{DEM analysis results and comparison with experimental results}

\subsection{Relationship of slope angle and slip}

The specific wheel condition of $D_{0}=200 \mathrm{~mm}, B=100 \mathrm{~mm}$, and $W=14.7 \mathrm{~N}$ was selected for calibration of DEM analysis so that the selected DEM parameters could be verified sufficiently to obtain comparable results from experiments.

Figure 6(a) shows the result of a wheel with $L_{H}=10 \mathrm{~mm}$ and $L_{n}=18$. A large difference between DEM analysis and experiments can be seen at a slope of $15 \mathrm{deg}$, where the slip difference reaches $20 \%$. Figure 6(b) indicates a smaller wheel slip with $L_{H}=20 \mathrm{~mm}$ and the same $L_{n}=18$ at a slope of $25 \mathrm{deg}$ in both DEM analysis and experiments. The largest slip difference between DEM and experiments is $16.3 \%$ at a slope of $20 \mathrm{deg}$. In Fig. 6(c), DEM and experimental results show similar behavior, but the difference in slip becomes large at the slope angles of 15 and 25 degrees in the experimental results. Comparing experimental results with numerical ones in Fig. 6, it can be stated that the selected parameters listed in Table 5 are sufficient for the DEM analysis of wheel performance on sloped terrain. 


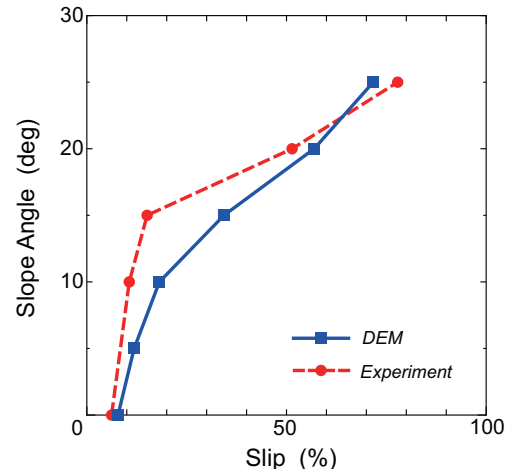

(a) $L_{n}=18$ and $L_{H}=10 \mathrm{~mm}$

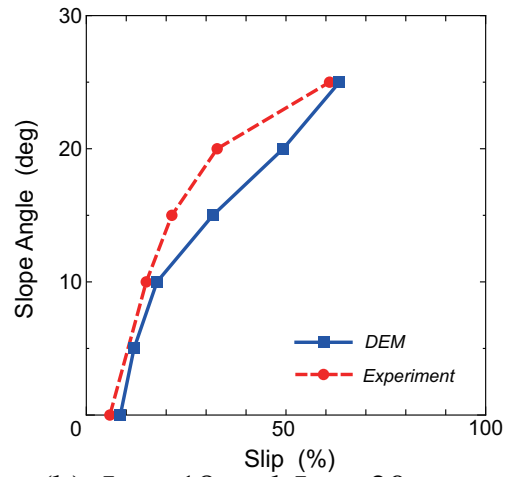

(b) $L_{n}=18$ and $L_{H}=20 \mathrm{~mm}$

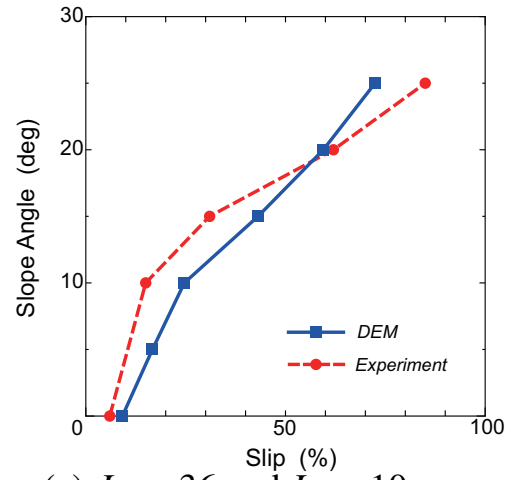

(c) $L_{n}=36$ and $L_{H}=10 \mathrm{~mm}$

Fig. 6. Result of slip and slope (1)

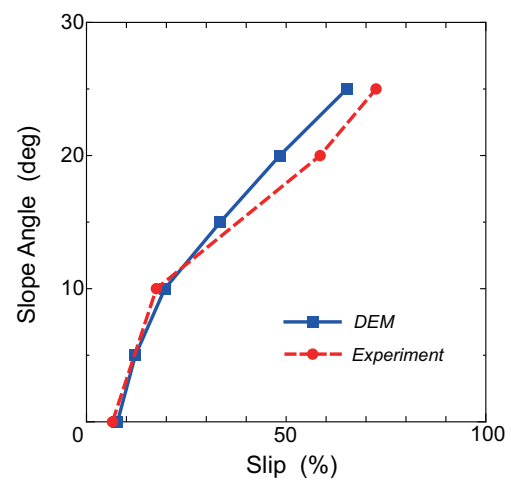

Fig. 7. Result of slip and slope (2)

To further verify the performance of DEM, a wheel with a larger vertical contact load of $W=19.6 \mathrm{~N}$ with $L_{H}=20 \mathrm{~mm}$ and $L_{n}=18$ was analyzed and the result of DEM was compared with recent experimental results [12], as shown in Fig. 7. The figure clearly indicates that the current DEM analysis can be applied with sufficient accuracy over a wide range of experimental conditions.

\subsection{Relationship of slope angle and wheel sinkage}

Experimental results for the wheel with $L_{H}=20 \mathrm{~mm}$ and $L_{n}=18$ for slopes of 10, 15, 20, and $25 \mathrm{deg}$ are shown in Fig. 8. The straight solid lines indicate the ideal slope lines for the given caption: blue for $10 \mathrm{deg}$, green for $15 \mathrm{deg}$, purple for $20 \mathrm{deg}$, and red for $25 \mathrm{deg}$. It is clear that the wheel on a $25 \mathrm{deg}$ slope travels with significant wheel slip and sinkage; the wheel travel is equivalent to that over the terrain with a slope of $20 \mathrm{deg}$. The DEM result (dashed lines) also indicates a similar reduction in wheel travel equivalence from $25 \mathrm{deg}$ to $20 \mathrm{deg}$, as shown in Fig. 8. Other wheel conditions, such as $L_{H}=10 \mathrm{~mm}$ and $L_{n}=36$, showed a similar equivalence in the results of experiments and DEM to that seen in Fig. 8. Thus, a slope of 20-25 deg might be the maximum for wheel locomotion. 


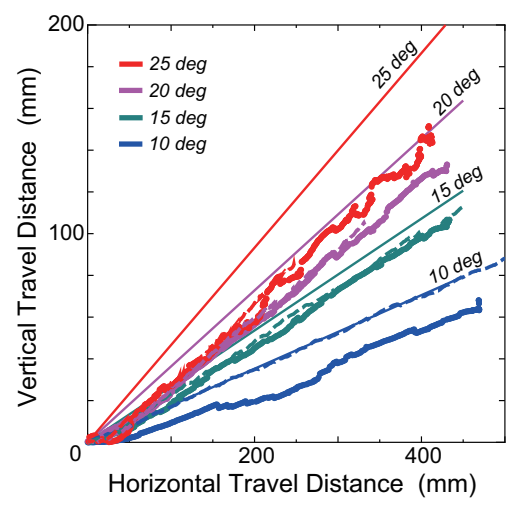

Fig. 8. Experimental and numerical wheel sinkage on sloped terrain

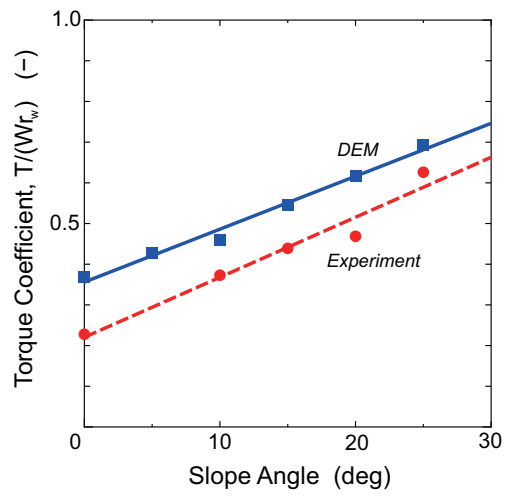

Fig. 9. Slope angle and wheel torque

\subsection{Relationship of slope angle and wheel torque}

Figure 9 shows the relationship between the slope angle and torque coefficient. The wheel is $D_{0}=200 \mathrm{~mm}, L_{H}=20 \mathrm{~mm}, L_{n}=18, B=100 \mathrm{~mm}$, and $W=14.7 \mathrm{~N}$. DEM analysis obtains the wheel torque $T$ as $T=H r_{w}$, where $H$ is the gross traction, and $r_{w}$ is the freely rolling radius of the wheel, which is assumed to be $r_{w}=D / 2$. The torque coefficient is then calculated as $T /\left(W r_{w}\right)=\left(H r_{w}\right) /\left(W r_{w}\right)=H / W$. In DEM, the wheel torque may be obtained directly from the wheel contact reaction. However, the DEM program in this study shares a common subroutine for contact reaction with that in our previous study [24]. Therefore, this study does not use the wheel torque directly obtained at the wheel element. The torque coefficient obtained by DEM analysis overestimates the experimental result by as much as of 0.15 , although both show a similar linear increase with respect to the slope angle. 


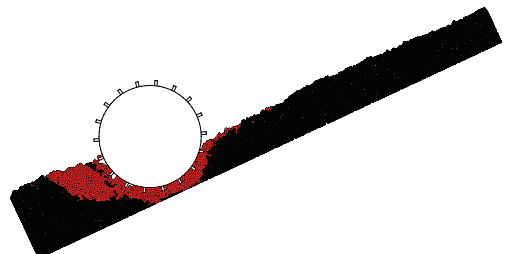

(a) Wheel No. $1(i=84.2 \%)$

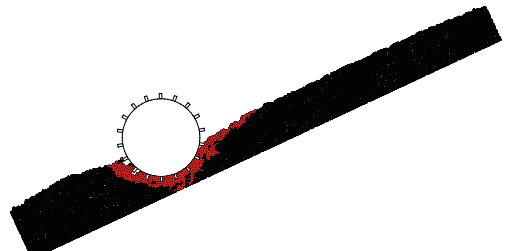

(d) Wheel No. $4(i=80.5 \%)$

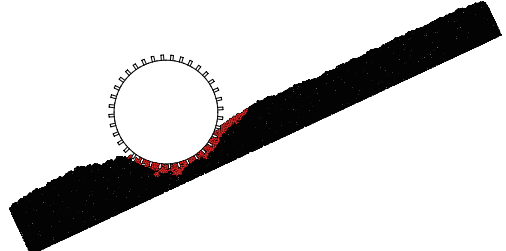

(g) Wheel No. $7(i=78.4 \%)$

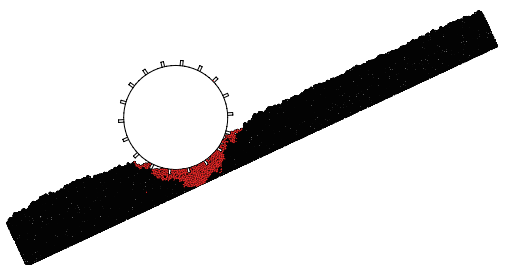

(b) Wheel No. $2(i=73.4 \%)$

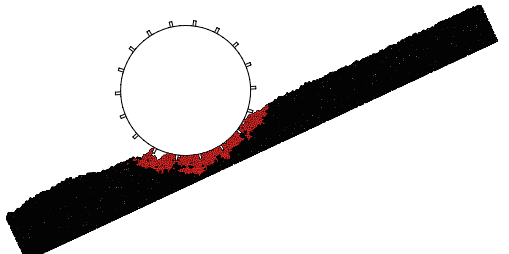

(e) Wheel No. $5(i=68.8 \%)$

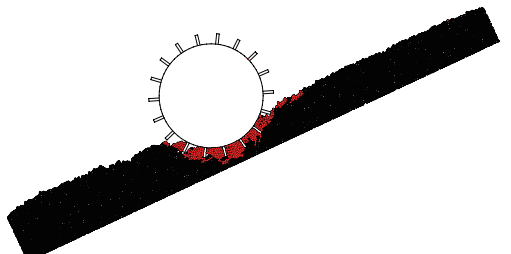

(h) Wheel No. $8(i=65.2 \%)$

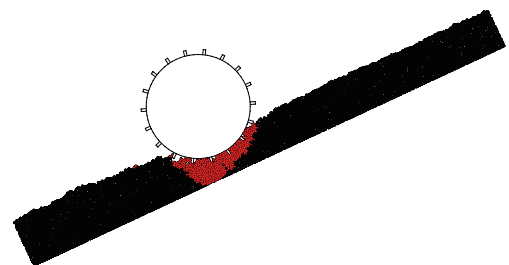

(c) Wheel No. $3(i=68.8 \%)$

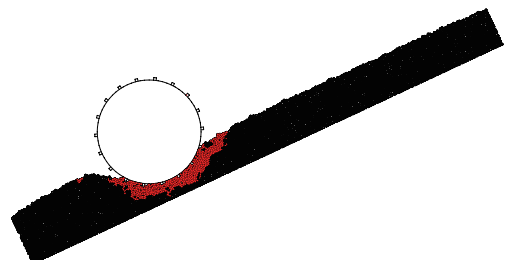

(f) Wheel No. $6(i=83.5 \%)$

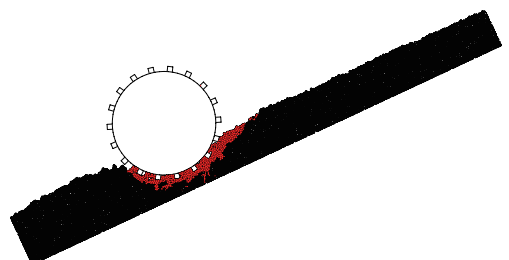

(i) Wheel No. $9(i=78.8 \%)$

Fig. 10. Instantaneous soil flow under a wheel on 25-degree slope

\section{Parametric investigation of lugged wheel performance on a sloped terrain by DEM}

\subsection{Remarks on soil flow under a wheel}

Figure 10 shows the DEM result of instantaneous soil flow on 25-degree slope for each wheel in Table 1 . The red region expresses the soil elements whose displacement becomes larger than $1 \mathrm{~mm}$ within a time step of $0.1 \mathrm{sec}$. Comparing the results for wheel numbers 1 to 3 [Figs. 10(a) to (c)] clearly shows that an increase in wheel width contributes to the prevention of sinkage. Moreover, the red region, indicating the area activated by lugs, clearly did not extend widely but remained close to the lug area in Figs. 10(g) to (i). Because of the effect of soil flow between or under the wheel lugs and the induced instability of soil with respect to internal friction angle, the figure shows that the soil element in front of the wheel flows by itself. Note that similar activated region with slip is seen in Figs 10(g) and 10(i) at the same coefficient of $C_{l}=28.6 \%$ for $D_{0}=200 \mathrm{~mm}$.

With respect to the bottom baseline of soil bin, an outline of mobilized zone of soil reaches to the bottom and is distorted in case of wheel number 1 because of the increased slip and sinkage of the wheel as seen in Fig. 10(a). Other wheels would not suffer significant effect of bottom wall of soil bin in terms of their outline shapes. For the effect of different diameter of wheel, wheel number 4 with small diameter 


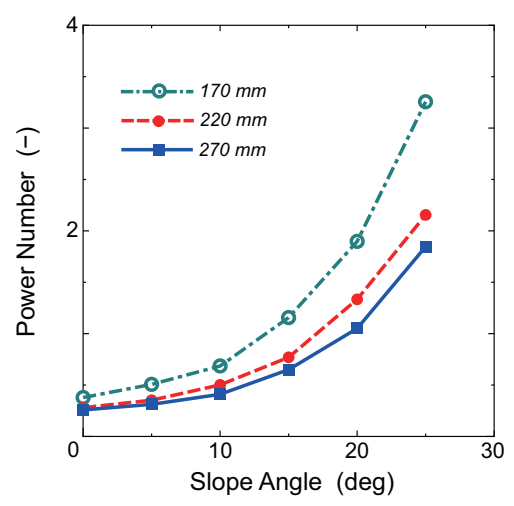

Fig. 11. Effect of the wheel diameter on the power number

[Fig. 10(d)] shows large sinkage, while wheel number 5 with large diameter [Fig. 10(e)] portrays small sinkage. The outline of mobilized zone under wheel number 5 expands widely, and that for wheel number 4 also grows wide under the wheel, because of increased slip and sinkage. On the other hand, wheel number 7 with $L_{n}$ $=36[$ Fig. $10(\mathrm{~g})]$ shows the smallest mobilized zone of soil in all wheel conditions, caused by the action of densely distributed lugs.

\subsection{Effect of the wheel diameter on the power number}

Figure 11 shows the effect of the wheel diameter $D$ on the $P N$, with DEM result for wheels with $D_{0}=150,200$, and $250 \mathrm{~mm} ; L_{H}=10 \mathrm{~mm} ; L_{n}=18 ; B=100 \mathrm{~mm}$; and $W=19.6 \mathrm{~N}$. In DEM, the circumferential velocity at the end of the lug was kept constant at $1.52 \mathrm{~cm} / \mathrm{s}$ by adjusting the angular velocity $\omega$ to observe the geometrical effect of the wheel diameter.

For the largest difference in $P N$ at a slope of 25 degrees, each DEM result is summarized as follows: the gross traction for cases of $D_{0}=150,200$, and $250 \mathrm{~mm}$ is $12.45,11.25$, and $10.78 \mathrm{~N}$ respectively. Similarly, the running resistance is 4.15 , 2.94 , and $2.48 \mathrm{~N}$ respectively. Moreover, the average sinkage is $2.04,1.71$, and 1.53 $\mathrm{cm}$ respectively. Thus, it is understood that, since a larger wheel diameter increases the contact area of the wheel under the same vertical contact load $W$ and net traction $P_{d}$, wheel sinkage would be reduced, resulting in a smaller rolling resistance and slip at larger slope angles.

\subsection{Effect of wheel load on the power number}

The simulation result for a wheel when $W=9.8,14.7$, and $19.6 \mathrm{~N} ; L_{n}=18 ; D_{0}=$ $200 \mathrm{~mm} ; B=100 \mathrm{~mm}$, is shown in Fig. 12. In Fig. 12(a), $L_{H}=10 \mathrm{~mm}$, and in Fig. $12(\mathrm{~b}), L_{H}=20 \mathrm{~mm}$. 


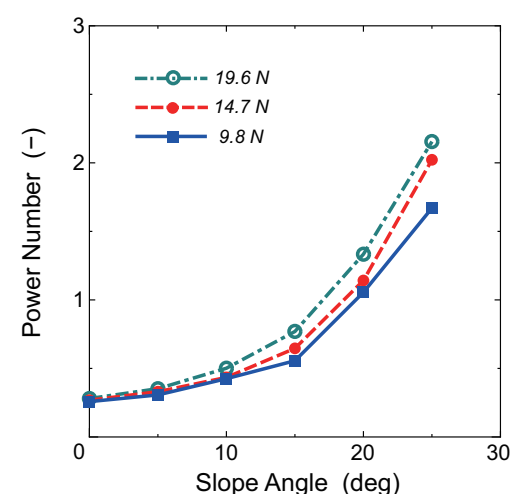

(a) $L_{H}=10 \mathrm{~mm}$

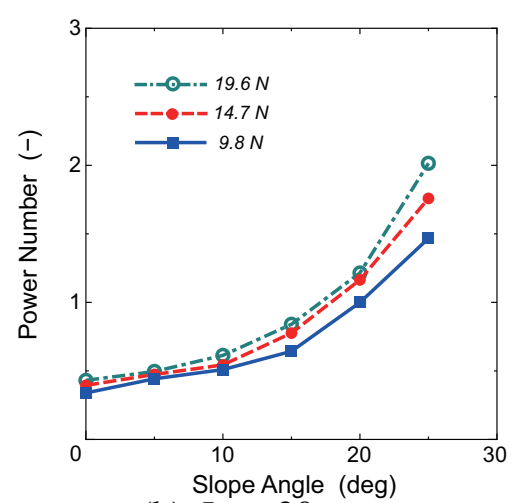

(b) $L_{H}=20 \mathrm{~mm}$

Fig. 12. Effect of wheel load on the power number

It is evident that the $P N$ is reduced if the wheel load is low. For example, for the 25 degree slope shown in Fig. 12(a), the average sinkage $z_{a}$ and the running resistance $R_{r}$ were $1.18 \mathrm{~cm}$ and $1.46 \mathrm{~N}$ for $W=9.8 \mathrm{~N}, 1.59 \mathrm{~cm}$ and $2.18 \mathrm{~N}$ for $W=14.7 \mathrm{~N}$, $1.71 \mathrm{~cm}$ and $2.94 \mathrm{~N}$ for $W=19.6 \mathrm{~N}$. However, the ratio of $H / W$, i.e. the torque coefficient as stated in 4.3, remained almost constant at $0.572-0.574$. The low contact load $W$ results in small wheel sinkage for a given slope, which contributes to the low running resistance $R_{r}$. The low running resistance implies low wheel slip, which reduces the $P N$. The difference in $P N$ for $14.7 \mathrm{~N}$ and $19.6 \mathrm{~N}$ decreases at a slope of $20 \mathrm{deg}$. Moreover, at slope angles of 0 and $5 \mathrm{deg}$, the $P N$ difference for various $W$ also decreases.

\subsection{Effect of wheel width on power number}

Figure 13 summarizes the simulation result for wheels with $B=50,100$, and 150 $\mathrm{mm} ; L_{H}=10 \mathrm{~mm} ; L_{n}=18 ; D_{0}=200 \mathrm{~mm}$; and $W=19.6 \mathrm{~N}$. The figure shows the effect of wheel width $B$ on the $P N$. In all cases, if the wheel width increases, the $P N$ decreases because of reduced wheel sinkage, reduced running resistance, and, therefore, of reduced wheel slip, as $i=84.2 \%$ for a $50-\mathrm{mm}$-wide wheel and $i$ $=68.8 \%$ for a $150-\mathrm{mm}$-wide wheel. Note that the difference in $P N$ between widths of 100 and $150 \mathrm{~mm}$ is not as large as the difference between 50 and $100 \mathrm{~mm}$, when $L_{n}=18$ [Fig. 13(a) and (b)]. Among the three wheel conditions, a wheel with $L_{n}=$ $18, L_{H}=10$ or $20 \mathrm{~mm}$ would be effective in terms of a low $P N$. From the figure, it is evident that the effect of wheel width may not be linear for some given slope angles and that an optimum wheel width may exist. The latter is due to increasing motion resistance from bulldozing for increased wheel width, offsetting the reduced sinkage. 


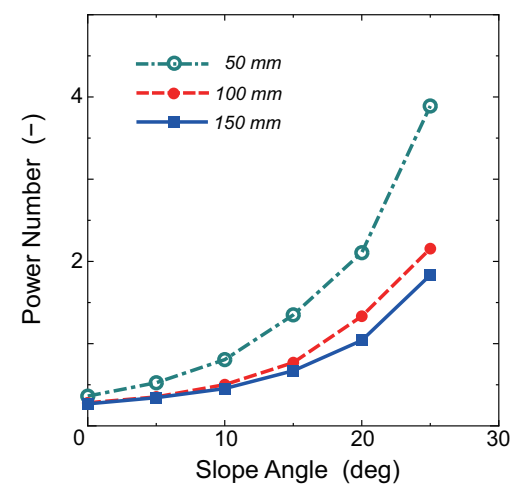

(a) $L_{n}=18$ and $L_{H}=10 \mathrm{~mm}$

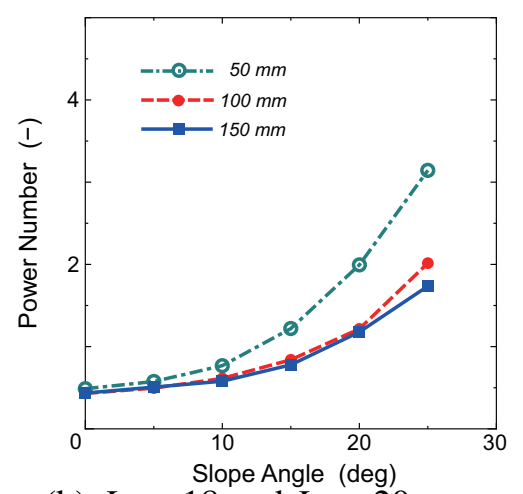

(b) $L_{n}=18$ and $L_{H}=20 \mathrm{~mm}$

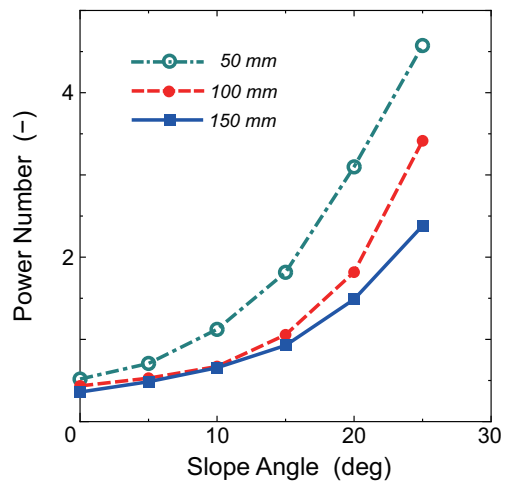

(c) $L_{n}=36$ and $L_{H}=10 \mathrm{~mm}$

Fig. 13. Effect of wheel width on the power number

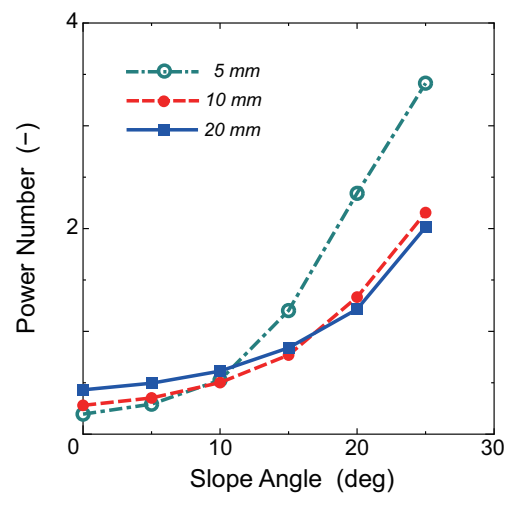

Fig. 14. Effect of lug height on the power number

\subsection{Effect of lug height on the power number}

Figure 14 illustrates the effect of lug height on the $P N$ for $L_{n}=18, D_{0}=200$ $\mathrm{mm}$, and $W=19.6 \mathrm{~N}$. The $P N$ curve is lower for a lug height of $L_{H}=10$ or $20 \mathrm{~mm}$, clearly showing that a higher lug height may be more effective for slope locomotion.

In Fig. 14, it is noted that the curve for lug height of $L_{H}=20 \mathrm{~mm}$ indicates largest power number among three lug height conditions for smaller slips below or equal 


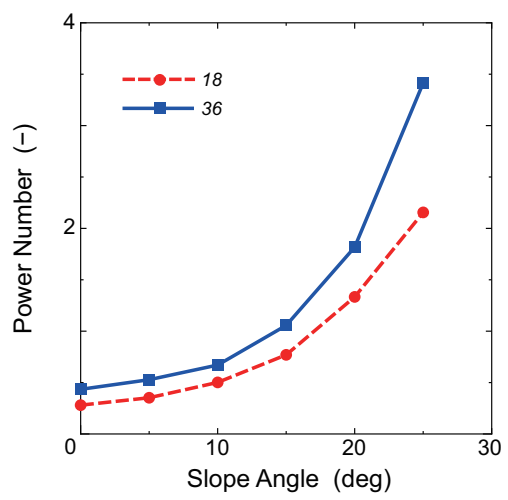

Fig. 15. Effect of lug number on the power number

to $10 \%$. This would imply the possibility of trade-off between power consumption on horizontal terrain and that on sloped terrain for $L_{H}=20 \mathrm{~mm}$.

A wheel with $L_{H}=20 \mathrm{~mm}$ [Fig. 10(h)] shows a narrow range of activated soil region that is mostly confined by the action of lugs within the outer most diameter of wheel $D$ to create a clear line of shear. For wheels with smaller lug height [e.g. Fig. 10(f)], although the zone of mobilized soil extends outside of $D$, the soil around the wheel also becomes activated and the wheel itself does not generate larger gross traction through the action of its lugs because of the reduced friction coefficient of 0.5 between the lug or wheel rim and soil elements; this increases wheel slip and thus the power number.

\subsection{Effect of the total numbers of lugs on the power number}

Figure 15 shows the simulation result for a wheel with $L_{n}=18$ and 36 while using $L_{H}=10 \mathrm{~mm}, D_{0}=200 \mathrm{~mm}, W=19.6 \mathrm{~N}, L_{T}=5 \mathrm{~mm}$, and $B=100 \mathrm{~mm}$. The effect of the number of lugs on the $P N$ is clearly seen-the wheel with $L_{n}=18$ has a better $P N$ than that with $L_{n}=36$.

To rationally describe the contributing mechanism of total number of lugs $L_{n}$, the coefficient $C_{l}$ of different wheels is compared. From Table 1, the coefficient $C_{l}$ for wheel number 2 is $14.3 \%$, while that for wheel number 7 is $28.6 \%$. In terms of the effect of the total number of lugs, a larger coefficient $C_{l}$ means that the ratio of the soil part within the contact area of wheel becomes small. However, the lug faces, acting as a soil cutting tool, generate the gross traction in a lugged wheel. Moreover, the bottom lug face contributes to soil compaction that affects the wheel running resistance. From these conditions, the result of gross traction for wheel number 7 becomes $H=14.45 \mathrm{~N}$ while generating $R_{r}=6.14 \mathrm{~N}$ as a negative effect. Thus, by cancelling the benefit of gross traction with running resistance under a small ratio of soil, the wheel with $L_{n}=36$ displayed a lower performance in terms of its $P N$.

Within the combination of investigated parameters, a larger wheel with fewer lugs 


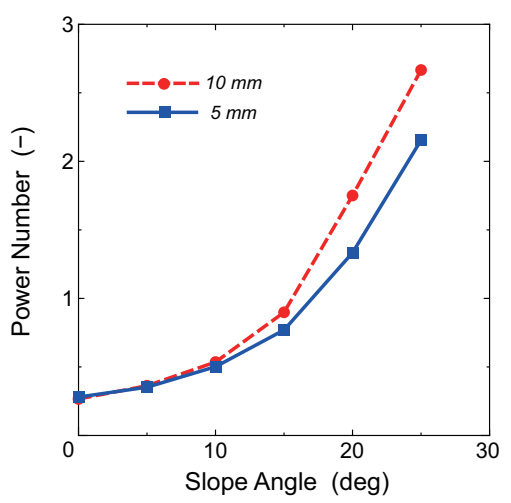

Fig. 16. Effect of the lug thickness on the power number

(e.g., $D_{0}=250 \mathrm{~mm}$ and $L_{n}=18$ ) may be suitable for a lunar micro rover in terms of the total wheel mass. Note that when the wheel diameter increases, e.g., to 300 $\mathrm{mm}$, the effect of the number of lugs on the $P N$ may differ, since the number of lugs within the contact area under the wheel will be small for $L_{n}=18$.

\subsection{Effect of the lug thickness on the power number}

Figure 16 shows the simulation result for a wheel with $L_{n}=18, L_{H}=10 \mathrm{~mm}, D_{0}=$ $200 \mathrm{~mm}, W=19.6 \mathrm{~N}, B=100 \mathrm{~mm}$, when the lug thickness is either $L_{T}=5$ or 10 $\mathrm{mm}$. It is clear that the effect of thickness on the $P N$ is almost the same for slope angles up to 10 degrees. For slope angles steeper than 10 degrees, a wheel with $L_{T}$ $=5 \mathrm{~mm}$ shows better performance in terms of the $P N$, but the difference in $P N$ for a slope of $25 \mathrm{deg}$ might be not so large, since there is only a slight difference in coefficient $C_{l}$ and of wheel slip, which would contribute to the difference, and other factors, such as the average sinkage, gross traction, and running resistance, had almost the same values for two values of $L_{T}$. The coefficient $C_{l}=28.6 \%$ for $L_{T}=10 \mathrm{~mm}$ is the same as that for the wheel with $L_{n}=36$ (wheel number 7 in Table 1), and the wheel might become similar to a wheel with almost no lug effect. For such cases, the generation of gross traction in DEM may depend on the friction coefficient $\mu^{L}$ between the wheel and soil rather than the friction coefficient $\mu$ between soil DEs.

\subsection{Remarks on lug parameters in relation with metrics}

From the parametric observations in this section, the effect of the lug parameters are summarized in Table 6, using the representative metrics for wheel performance, such as $\theta_{20 \%}, P N_{S P}, P N_{15 d e g}$ and $P N_{20 \%}$ [4] for each wheel under $W=19.6 \mathrm{~N}$.

For slope angle at $20 \%$ slip $\left(\theta_{20 \%}\right)$, the wheel performance is regarded as better if its angle increases. For other metrics, the wheel has better power consumption, if 
Table 6

Representative metrics with superiority weight

\begin{tabular}{|c|c|c|c|c|c|c|c|c|c|}
\hline Wheel No. & $\theta_{20 \%}(\operatorname{deg})$ & & $P N_{S P}$ & & $P N_{15 \text { deg }}$ & & $P N_{20 \%}$ & & Sum of weights \\
\hline 1 & 0.49 & 8 & 0.363 & 6 & 1.350 & 9 & 0.376 & 2 & $(25)$ \\
\hline 2 & 7.10 & 3 & 0.280 & 5 & 0.790 & 3 & 0.414 & 4 & 15 \\
\hline 3 & 10.0 & 1 & 0.268 & 4 & 0.670 & 2 & 0.453 & 6 & (13) \\
\hline 4 & 3.70 & 6 & 0.379 & 7 & 1.156 & 7 & 0.475 & 7 & (27) \\
\hline 5 & 9.35 & 2 & 0.258 & 2 & 0.650 & 1 & 0.396 & 5 & 10 \\
\hline 6 & 2.72 & 7 & 0.195 & 1 & 1.203 & 8 & 0.246 & 1 & (17) \\
\hline 7 & 5.87 & 5 & 0.434 & 9 & 1.056 & 6 & 0.554 & 8 & (28) \\
\hline 8 & 10.0 & 1 & 0.431 & 8 & 0.840 & 4 & 0.620 & 9 & $(22)$ \\
\hline 9 & 6.30 & 4 & 0.266 & 3 & 0.899 & 5 & 0.391 & 3 & 15 \\
\hline Average & 6.17 & & 0.319 & & 0.955 & & 0.436 & & \\
\hline
\end{tabular}

the $P N$ decreases. An order of superiority is also shown by a simple integer for each metric, where a smaller number is input for higher performance. The last column in Table 6 summarizes the sum of four numbers, which implies the lowest sum might be regarded as the best wheel in terms of the four corresponding metrics. The sum with brackets indicates that some metrics in the table are out of the preferred range.

Comparing the metrics with respect to the corresponding average values shows that wheel numbers 2, 5 and 9 may be candidates for lugged wheels for the small lunar rovers under study. Wheel numbers 2 and 5 have similar lug parameters with different wheel diameters; $D_{0}=20 \mathrm{~cm}$ for the wheel number 2 and $D_{0}=25 \mathrm{~cm}$ for number 5 . In terms of the smallest sum of weights, wheel number 5 may be a candidate wheel within the lug parameters investigated in this section. The selection of wheel number 5 may be the same result as in our previous DEM analysis on horizontal terrain [24]. Note that the diameter $D$ of the wheel should be determined from other requirements, such as stowage of the rover vehicle in the lander.

The performance from DEM of a lugged wheel on a slope of 25 degrees, the result of tractive performance, such as gross traction $H$, net traction $P_{d}$, running resistance $R_{r}$ and average sinkage $z_{a}$, which was integrated from the beginning of wheel rotation and end of wheel travel, is summarized in Table 7 . The table verifies that wheel number 5 exhibits the best traction performance under the lug conditions examined, in terms of small running resistance and average sinkage. Wheel number 8 ( $L_{H}=20 \mathrm{~mm}$ and $\left.L_{n}=18\right)$ and wheel number $7\left(L_{H}=10 \mathrm{~mm}\right.$ and $L_{n}=36$ ) not only increased the gross traction but also increased running resistance while indicating the same average level of wheel sinkage.

It is noted that the effect of cohesion, which is not considered in the present DEM 
Table 7

Performance of lugged wheel on 25-degree slope

\begin{tabular}{cccccc}
\hline Wheel No. & $i(\%)$ & $H(\mathrm{~N})$ & $P_{d}(\mathrm{~N})$ & $R_{r}(\mathrm{~N})$ & $z_{a}(\mathrm{~cm})$ \\
\hline 1 & 84.2 & 12.04 & 8.31 & 3.73 & 2.47 \\
2 & 73.4 & 11.25 & 8.31 & 2.94 & 1.71 \\
3 & 68.8 & 11.23 & 8.31 & 2.92 & 1.57 \\
4 & 80.5 & 12.45 & 8.30 & 4.15 & 2.04 \\
5 & 68.8 & 10.78 & 8.30 & 2.48 & 1.53 \\
6 & 83.5 & 11.06 & 8.29 & 2.77 & 1.67 \\
7 & 78.4 & 14.45 & 8.31 & 6.14 & 1.65 \\
8 & 65.2 & 13.74 & 8.30 & 5.44 & 1.65 \\
9 & 78.8 & 11.10 & 8.29 & 2.81 & 1.69
\end{tabular}

analysis, may become important in comparison of tractive performance of wheels with different contact areas as observed by $z_{a}$.

\section{Prediction of lugged wheel performance on sloped lunar terrain}

\subsection{Introduction}

The locomotion over lunar terrain has been a challenging topic for vehicle engineers ever since the US Apollo mission and the Luna mission of the USSR. The robotic rover Lunokhod 2 sank significantly in the vicinity of some craters, and the Apollo 15 LRV encountered isolated soft soil and became stuck [30]. Thus, predictions of wheel performance and the prospective rover design should take into account maneuverability in soft soil conditions.

The performance of a wheel on sloped lunar soft terrain is simulated using the selected wheel parameters $\left(D_{0}=250 \mathrm{~mm} ; B=100 \mathrm{~mm} ; L_{H}=10 \mathrm{~mm} ; L_{T}=5 \mathrm{~mm}\right.$; $\left.L_{n}=18\right)$ under a vertical contact load of $W=14.7 \mathrm{~N}$. To observe the soil condition, the same contact load of $W$ is used for both lunar terrain and earth terrain, which means the drawbar load $P_{x}$ also becomes the same on the Earth and on the Moon depending on the slope angle.

Since adopting the same wheel contact load both for the Moon and Earth is expected to produce greater wheel sinkage, the initially generated thickness of soil DEs is increased to $15 \mathrm{~cm}$, where the total number of soil DEs is 9980 . Moreover, the length of the soil bin was extended, and for sloped terrain analysis the wheel was positioned in the middle of the soil bin to avoid the disturbance of soil flow 


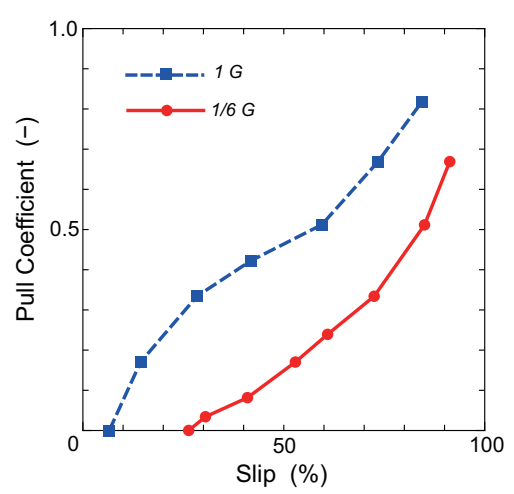

Fig. 17. Pull coefficient on horizontal terrain

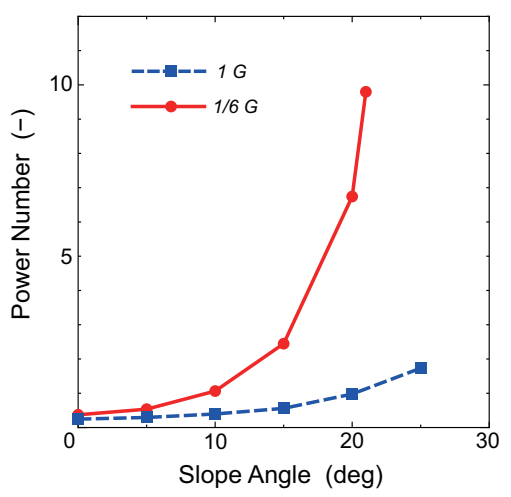

Fig. 18. Effect of gravitational acceleration on the power number

caused by its side walls. This produced a total of 15980 soil DEs for sloped lunar terrain analysis.

\subsection{Pull coefficient obtained from the horizontal terrain condition}

Firstly, the performance of wheel was obtained on the horizontal terrain. Various drawbar loads were input to simulate tractive performance of the wheel in 2D DEM [24]. The pull coefficient $P / W$ at $1 / 6 \mathrm{G}$ is shown in Fig. 17 along with the result at $1 \mathrm{G}$. From the figure, it is clear that the weak, or soft, condition of soil on the lunar gravity results in the increased sinkage of wheel and, thus, decreased output of pull coefficient. The slip of $26.3 \%$ for a zero pull coefficient at $1 / 6 \mathrm{G}$ indicates reduced wheel mobility on horizontal lunar terrain.

\subsection{Effect of gravitational acceleration on the power number}

Figure 18 shows the $P N$ under the effect of gravitational acceleration for slope locomotion. Note that the wheel cannot climb a slope of 25 degrees at $1 / 6 \mathrm{G}$. It is clear that the reduced gravity would increase the $P N$ at all slope angles. The 


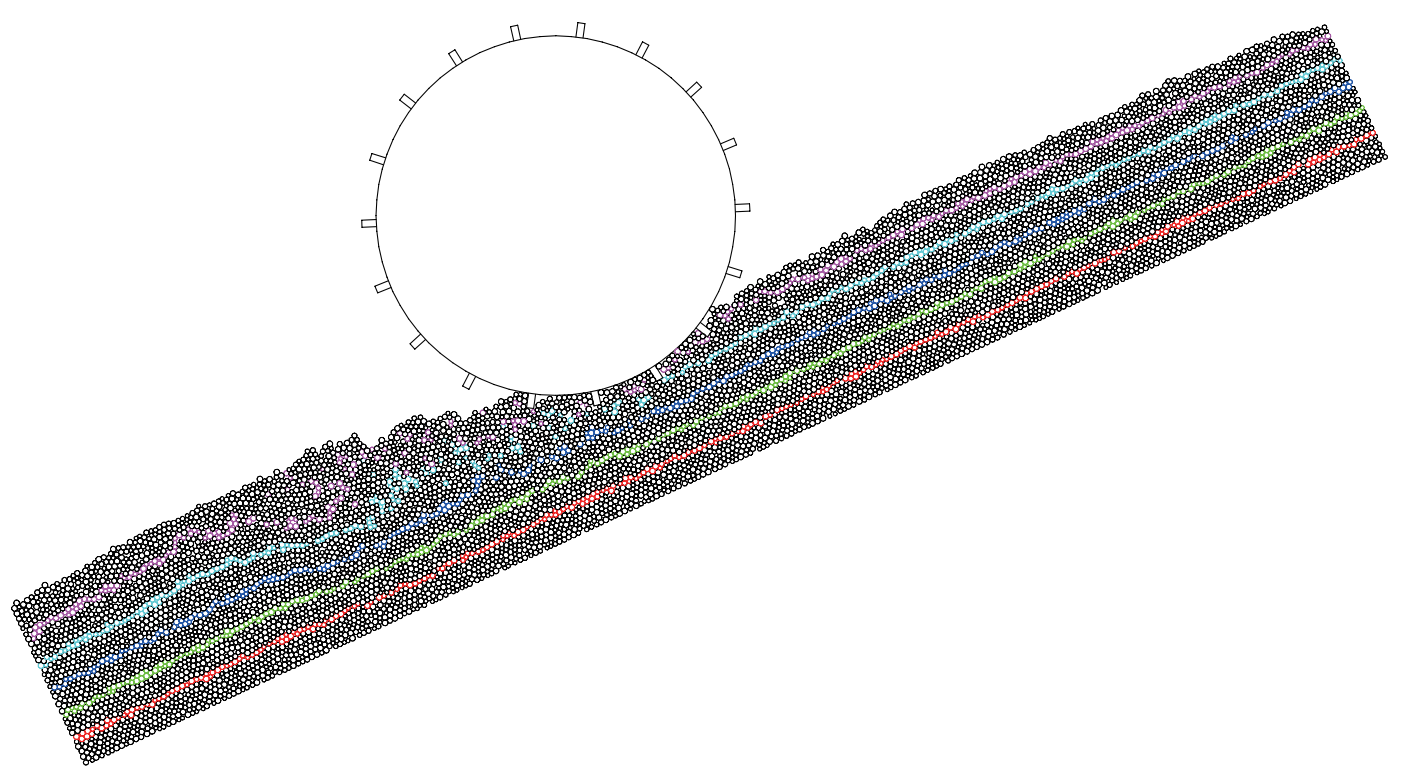

Fig. 19. Soil deformation under a wheel on a Earth slope of 25 degrees

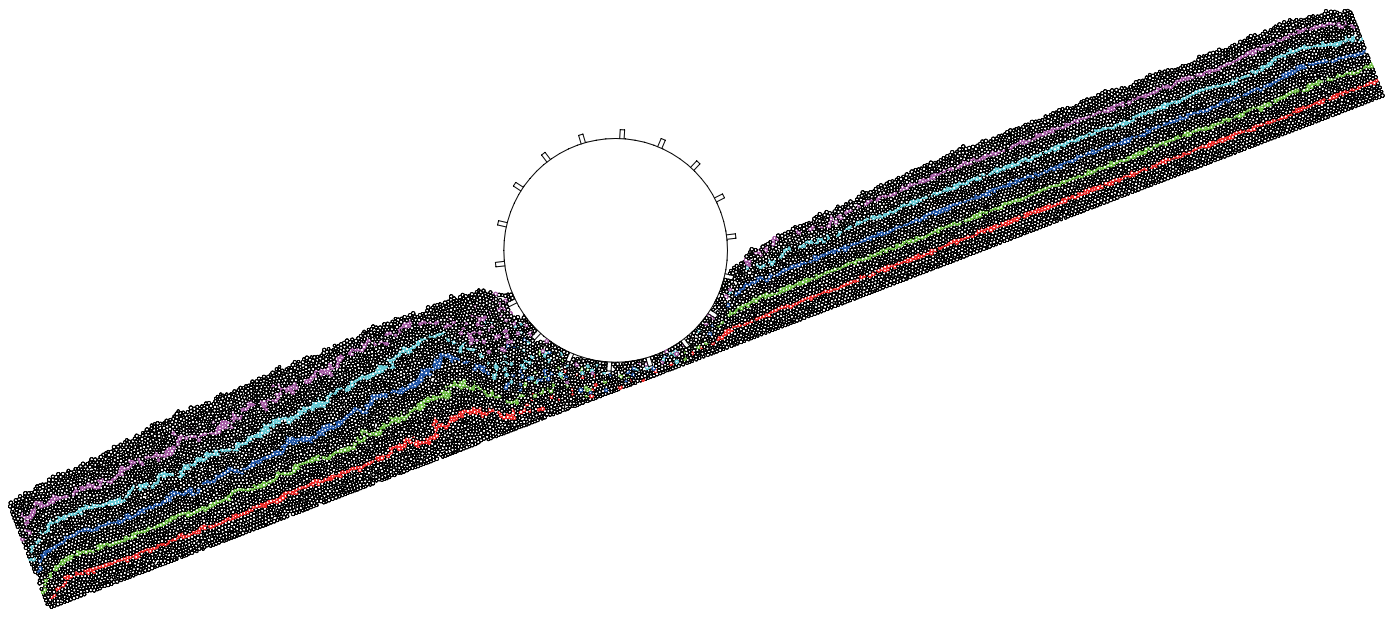

Fig. 20. Soil deformation under a wheel on a lunar slope of 21 degrees with extended soil bin condition

increased $P N$, especially for larger slope angles in the figure, implies an excessive energy expenditure due to the reduction of soil trafficability caused by reduced gravitational acceleration on the Moon.

\subsection{Comparison of soil deformation under the wheel}

Figure 19 shows the results of soil deformation for Earth gravity at a slope angle of $25 \mathrm{deg}$, where the wheel slip was $68.3 \%$. The result of soil deformation for lunar gravity at a slope angle of $21 \mathrm{deg}$ is shown in Fig. 20. In the figure, the slip was $94.4 \%$ at $1 / 6 \mathrm{G}$, and the wheel could not climb the slope angle at $25 \mathrm{deg}$ as it did at $1 \mathrm{G}$. In both figures, the vertical contact load condition is the same. 
The wheel sinks considerably with $z_{a}=3.01 \mathrm{~cm}$ at $1 / 6 \mathrm{G}$ because of the increased slip, since the weight of the soil element would be reduced by $1 / 6$, thereby reducing the compaction by its own weight even in the extended period of soil consolidation, as can be inferred from Fig. 20.

\subsection{Discussion}

It becomes clear that the candidate lugged wheel with $D_{0}=250 \mathrm{~mm}, B=100$ $\mathrm{mm}, L_{H}=10 \mathrm{~mm}, L_{T}=5 \mathrm{~mm}, L_{n}=18$ under $W=14.7 \mathrm{~N}$ might have difficulty climbing a lunar terrain sloped more than 20 degrees. This is mainly due to the reduced trafficability of soil in a lunar environment.

Moreover, the preparation of the initial soil condition is an issue in application of the DEM. In the previous study [4], the following items were proposed for the experiments with simulants. Important parameters were relative density, cohesion, angle of internal friction, and penetration resistance gradient. Cohesion and the angle of internal friction can be regarded as input parameters in DEM, but the effect of cohesion is not yet implemented in our present analysis. The relative density and the penetration resistance gradient can be obtained as a result of the analysis, although our present DEM does not include these output.

The consolidation in the first stage of DEM analysis was thought to be a governing factor of soil conditioning on bulk density in low gravity conditions [27]. An inverse proportional factor of six was multiplied to the consolidation time of earth conditions to increase the duration of consolidation for lunar gravity of $1 / 6 \mathrm{G}$ so that the soil DEs could be stabilized sufficiently by their own weight during consolidation. In the present analysis, however, the effect of extended time for lunar gravity could not be found because the initial generation of soil DEs was done in a rather dense configuration, where the fall height of each soil element could not be large. For the precise prediction of lugged wheel performance on the Moon, the preparation of initial condition of soil DEs should be investigated.

\section{Conclusions}

To confirm the applicability of DEM for sloped terrain locomotion, the relationships of slope angle with slip, wheel sinkage and wheel torque obtained by DEM, were compared with experimental results measured using a slope test bed consisting of a soil bin filled with lunar regolith simulant. Among the lug parameters investigated, a lugged wheel with $D_{0}=250 \mathrm{~mm}, B=100 \mathrm{~mm}, L_{H}=10 \mathrm{~mm}, L_{T}=$ $5 \mathrm{~mm}, L_{n}=18$ was found, on average, to have excellent performance in terms of metrics, such as $\theta_{20 \%}, P N_{S P}, P N_{15 d e g}$ and $P N_{20 \%}$. The estimation of wheel perfor- 
mance over sloped lunar terrain showed an increase in wheel slip, and a possibility that the selected lugged wheel might not have locomotion on a slope greater than 20 degrees.

The low gravity on the Moon resulted in reduction of frictional forces between soil particles, observed as the increase in sinkage of wheel. Consequently, the effect of cohesion would become more significant in lunar gravity. An investigation into the relative influence of cohesion both at $1 \mathrm{G}$ and at $1 / 6 \mathrm{G}$ using DEM is recommended. Moreover, successive study on metrics for all wheel candidates in lunar gravity by DEM is suggested to verify the effect of gravity on wheel parameters decided in this analysis.

\section{Acknowledgements}

This research was in part funded by NASDA, currently JAXA, as the cooperative research project for 2000-2003. The cooperation of the Chofu Aerospace Center (CAC), JAXA, is fully acknowledged for allowing the use of the sloped test bed for the experiment.

\section{References}

[1] JAXA. Vision-JAXA 2025-. http://www.jaxa.jp/about/2025/index_e.html, accessed on March 8, 2008.

[2] Nishida S, Wakabayashi S. A study on mobility platform of lunar work rover. In: Preprints 26th Int. Symposium on Space Technology and Science, Hamamatsu, 2008: 2008-k-57. (CD-ROM)

[3] Fujii H. DEM analysis for a wheel of lunar rover and regolith system interaction. Unpublished Bachelor of Agric. Sci. Thesis, Faculty of Agriculture, Kyoto University, Kyoto, 2001. (in Japanese)

[4] Freitag DR, Green AJ, Melzer KJ, Costes NC. Wheels for lunar vehicles. Journal of Terramechanics 1972; 8(3): 89-105.

[5] Green AJ, Melzer KJ. Performance of the Boeing LRV wheels in a lunar soil stimulant-Report 1 Effect of wheel design and soil. Technical Report M-71-10, Mobility and Environmental Division, U. S. Army Engineer Waterways Experiment Station, Vicksburg, Mississippi, 1971.

[6] Melzer, KJ. Performance of the Boeing LRV wheels in a lunar soil stimulantReport 2 Effects of speed, wheel load, and soil. Technical Report M-71-10, Mobility 
and Environmental Division, U. S. Army Engineer Waterways Experiment Station, Vicksburg, Mississippi, 1971.

[7] Asnani V, Delap D, Creager C. The development of wheels for the Lunar Roving Vehicle. Journal of Terramechanics 2009; 46: 89-103.

[8] Wong JY, Asnani VM. Study of the correlation between the performances of lunar vehicle wheels predicted by the Nepean wheeled vehicle performance model and test data. Proc. IMechE, Part D: Journal of Automobile Engineering 2008; 222: 1939-1954.

[9] Richter L, Hamacher H. Investigation the locomotion performance of planetary microrovers with small wheel diameters and small wheel loads. In: Proc. 13th Int. Conf. ISTVS, Munich, 1999: 719-726.

[10] Richter L, Ellery A, Gao Y, Michaud S, Schmitz N, Weiss S. A predictive wheel-soil interaction model for planetary rovers validated in testbeds and against MER Mars rover performance data. In: Proc. 10th European Conf. ISTVS, Budapest, 2006: 1-27.

[11] Iizuka K, Sato Y, Kuroda Y, Kubota T. Study on traversability with consideration of wheeled forms for lunar and planetary exploration rovers. Trans. JSME 2006; 72(724): 148-153. (in Japanese)

[12] Wakabayashi S, Kohno Y, Nishida S. Evaluation of low-pressure mobility system for lunar vehicle. In: Preprints 26th Int. Symposium on Space Technology and Science, Hamamatsu, 2008: 2008-k-56. (CD-ROM)

[13] Cundall PA, Strack ODL. Discrete numerical model for granular assemblies. Géotechnique 1979; 29(1): 47-65.

[14] Johnson KL. Contact mechanics. Cambridge University Press, Cambridge, 1985.

[15] Mindlin RD, Deresiewicz H. Elastic spheres in contact under varying oblique forces. Journal of Applied Mechanics 1953; 20: 327-344.

[16] Sakaguchi E, Kawakami S, Tamura S, Tobita F. Simulation on discharging phenomena of grains by distinct element method-Influence of shapes of element on flowing states. Journal of The Japanese Society of Agricultural Machinery 1996; 58(4): 9-17. (in Japanese)

[17] Feng YT, Owen DRJ. An energy based corner to contact algorithm. Discrete Element Methods (Edited by Cook BK, Jensen RP), ASCE, 32-37, 2002.

[18] Asaf Z, Shmulevich I, Rubinstein D. Predicting soil-rigid wheel performance using distinct element methods. Transactions of the ASABE 2006: 49(3); 607-616.

[19] Horner DA, Peters JF, Carrillo A. Large scale discrete element modelling of vehiclesoil interaction. Journal of Engineering Mechanics 2001; 127(10): 10271032.

[20] Nakashima H, Konishi T, Toki Y. Numerical Analysis for Cone Penetration of Mesoscopic Soil Model. In: Proc. of the Joint North America, Asia-Pacific ISTVS Conference and Annual Meeting of Japanese Society for Terramechanics, Fairbanks, June 23-26, 2007: 2007-31-0319, 1-9. (CD-ROM) 
[21] Oida A, Ohkubo S, Schwanghart H. Effect of tire lug cross section on tire performance simulated by distinct element method. In: Proc. 13th Int. Conf. ISTVS, Munich, 1999: $345-352$.

[22] Oida A, Ohkubo S. Application of DEM to simulate interaction between soil and tire lug. Agricultural \& Biosystems Engineering 2000; 1(1): 1-6.

[23] Fujii H. An analysis of lugged wheel performance by DEM for the development of wheel for a lunar rover. Unpublished Master of Agric. Sci. Thesis, Division of Environmental Science \& Technology, Graduate School of Agriculture, Kyoto University, Kyoto, 2003. (in Japanese)

[24] Nakashima H, Fujii H, Oida A, Momozu M, Kawase Y, Kanamori H, Aoki S, Yokoyama T. Parametric analysis of lugged wheel performance for a lunar microrover by means of DEM. Journal of Terramechanics 2007; 44(2): 153-162.

[25] Li JQ, Zou M, Jia Y, Ma WZ, Ren LQ, Li YW. Research the interaction between the rigid wheel and the lunar soil by DEM. In: Proc. of the Joint North America, AsiaPacific ISTVS Conference and Annual Meeting of Japanese Society for Terramechanics, Fairbanks, June 23-26, 2007: 1-12. (CD-ROM)

[26] Hopkins MA, Johnson JB, Sullivan R. Discrete element modeling of a rover wheel in granular material under the influence of Earth, Mars, and Lunar Gravity. In: Proc. Earth \& Space 2008, 11th ASCE Aerospace Division International Conference on Engineering, Science, Construction, and Operations in Challenging Environments, Long Beach, March 3-5, 2008: 1-7. (CD-ROM)

[27] Nakashima H, Shioji Y, Kobayashi T, Aoki S. Numerical analysis of sand flow under low gravity condition. In: Proc. of the Joint North America, Asia-Pacific ISTVS Conference and Annual Meeting of Japanese Society for Terramechanics, Fairbanks, June 23-26, 2007: ISTVS-2007-62-0147, 1-10. (CD-ROM)

[28] Ji S, Shen HH. Contrasting terrestrial and lunar gravity: angle of repose and incline flows, In: Proceedings of 10th ASCE Aerospace Division International Conference on Engineering, Construction, and Operations in Challenging Environments, 2006: 1-8. $(\mathrm{CD}-\mathrm{ROM})$

[29] Wakabayashi S, Matsumoto K. Development of slope mobility testbed using lunar soil. JAXA Research and Development Memorandum, JAXA-RM-05-003, 2006: 1-11. (in Japanese)

[30] Heiken GH, Vaniman DT, French BM, Ed. Lunar sourcebook. Cambridge University Press, Cambridge, 1991.

[31] Willman BM, Boles WW, McKay DS, Allen CC. Properties of lunar soil simulant JSC-1. Journal of Aerospace Engineering, ASCE, 1995; 8(2): 77-87.

[32] Momozu M, Oida A, Yamazaki M, Koolen AJ. Simulation of a soil loosening process by means of the modified distinct element method. Journal of Terramechanics 2003; 39: 207-220. 
[33] Bui HH, Kobayashi T, Fukagawa R, Wells JC. Numerical and experimental studies of gravity effect on the mechanism of lunar excavations. Journal of Terramechanics 2009; 46: $115-124$. 